\title{
Epidemiological study of bovine fasciolosis using coprological technique in district Mardan, Khyber Pakhtunkhwa, Pakistan
}

Naimat Ullah Khan ${ }^{1 *}$, Samia Sultan ${ }^{2}$, Ihsan Ullah ${ }^{3}$, Hazrat Ali ${ }^{1}$, Mian Saeed Sarwar ${ }^{1}$, Anwar Ali ${ }^{4}$, Tahir Usman ${ }^{1}$, Azmat Ullah Khan ${ }^{5}$, Munib Hussain $^{6}$, Mehboob Ali ${ }^{7}$, Fazli Rabbani ${ }^{1}$ and Attaur Rahman ${ }^{1}$

1. College of Veterinary Sciences and Animal Husbandry, Abdul Wali Khan University Mardan, KP-Pakistan

2. Department of Zoology, Abdul Wali Khan University, Mardan-Pakistan

3. Department of Animal Health Agricultural University Peshawar-Pakistan

4. Veterinary Research Institute, Peshawar, KPK-Pakistan

5. Veterinary Officer (H) L\&DD Bannu-Pakistan

6. Pakistan Agriculture Research council Islamabad-Pakistan

7. Livestock and Dairy Development Department Quetta-Pakistan

*Corresponding author's email: naimatullahkhan19@yahoo.com,naimatullahkhan75@awkum.edu.pk

\section{Citation}

Naimat Ullah Khan, Samia Sultan, Ihsan Ullah, Hazrat Ali, Mian Saeed Sarwar, Anwar Ali, Tahir Usman, Azmat Ullah Khan, Munib Hussain, Mehboob Ali, Fazli Rabbani and Attaur Rahman. Epidemiological study of bovine fasciolosis using coprological technique in district Mardan, Khyber Pakhtunkhwa, Pakistan. Pure and Applied Biology. Vol. 9, Issue 1, pp455-463. http://dx.doi.org/10.19045/bspab.2020.90050

\begin{tabular}{llll}
\hline \hline Received: 10/08/2019 & Revised: 25/10/2019 & Accepted: 04/11/2019 & Online First: 14/11/2019 \\
\hline \hline
\end{tabular}

\section{Abstract}

The basic aim of the present study was to investigate the prevalence and the associated risk factors responsible for occurrence of bovine fasciolosis causing huge economic losses in cattle in district Mardan. A total of $(n=500)$ cattle of different age groups, breeds, sex and body condition score (BCS) were randomly selected for collection of feces and screened for presence of fasciola eggs using fecal sedimentation test. As a result, out of 500 cattle only $214(214 / 500=42.8 \%)$ were found positive for fasciola infection and overall prevalence was (42.8\%).Non-probability statistics was applied on obtained data at $5 \%$ probability. The total population $(n=500)$ was divided in to three age groups ( $\geq 1-3$ years, $4-6$ years and 7-9 years) where the highest prevalence was recorded at the age of $\geq 1-3$ years $(48.82 \%)$ followed by $4-6$ years $(39.74 \%)$ and the lowest at the age of $7-9$ years $(39.65 \%)$ and statistically highly significant association $(\mathrm{p}<0.001)$ was recorded. The breed wise study revealed the highest prevalence in cross Friesian cattle (46.78\%) than local cattle $(42.90 \%)$ and statistically non-significant $(\mathrm{p}>0.229)$ association was observed. The highest sex wise prevalence of bovine fasciolosis was recorded in female cattle $(49.03 \%)$ than male $(32.63 \%)$ and statistically significant association $(\mathrm{p}<0.003)$ was observed. Relationship between BCS and prevalence of bovine fasciolosis showed the highest rate of infection in those animals having poor body conditions $(49.54 \%$ ) followed by medium body conditions $(45.61 \%)$ while the lowest prevalence was recorded in those animals having good body conditions (37.27\%) and statistically 
non-significant association ( $\mathrm{p}>0.373$ ) was recorded. As a result it was concluded that bovine fasciolosis was highly prevalent in the study area causing a huge economic losses and it should be mentioned in priority list for chemotherapy and preventive measures.

Keywords: BCS; Fasciola; Lymnea; Snails; Trematodes

\section{Introduction}

In Pakistan, livestock is the backbone of economic sector and the integral part of agricultural sector which is the second largest sector; that almost adds $56.3 \%$ shares to agricultural added value. In livestock and agriculture more than 35 million populations are involved which donates approximately $11 \%$ to the total the national GDP. In Pakistan more than $62 \%$ of population are living in rural areas who are where directly or indirectly involved in Agro- livestock sector for their livelihood. According to our national herd survey the total number of cattle, buffalo, goat, sheep and camels are 29.6, 27.3, 53.8, 26.5 and 0.9 million while in district Mardan the total population of cattle are 2447445 [1]. Among all the parasitic diseases, fasciolosis is one of the major parasitic disease causing a huge economic losses, caused by trematodes belonging to genus Fasciola where migration occur in hepatic parenchyma and final development and establishment occur in bile duct [2]. The parasitic infestation is an emerging infection in livestock and human health directly or indirectly affecting economic sector globally [3]. Among all animal disease, parasitic infections are major constrain in economic development [4]. Fasciolosis is the major parasitic infection which enforces economic impact on production cattle and sheep [5]. The most common etiological species of Fasciola are Fasciola hepatica and Fasciola gigantica. Fasciolosis has been reported in all domestic animals, human beings and other wild species but severe economic losses observed in small ruminants. Its direct economic losses have been reported in the form of condemnation of liver, decrease in production of milk, lower weight calves at birth, poor weight gain and cost of treatment.
The intermediate host snails (genus Lymnaea) play important role in spread of fasciolosis [6].

The important aquatic snails act as an intermediate host for Fasciola gigantica are Lymnaea natalensis while for Fasciola hepatica is L. truncatula, an amphibious snail. All snails can live and breed at $10^{\circ} \mathrm{C}$.Other environmental conditions such as heavy rainfall, open grazing, poor control system for snails and heavy water availability [7].The life cycle of both species of digenetic trematodes has been recorded by indirect life cycles [8].

Prophylactic programs can play an important role to control fasciolosis if based on local epidemiological data in Pakistan. Therefore the present study was conducted to estimate the prevalence of fasciolosis in Mardan and identify the associated risk factors responsible for bovine fasciolosis in district Mardan, KPK, Pakistan.

\section{Materials and methods}

\section{Description of the study area}

The present study was conducted in district Mardan which is positioned in the southern west of Khyber Pakhtunkhwa. It is located at level of $34^{\circ} 12^{\prime} 0 \mathrm{~N} 72^{\circ} 11^{\prime} 60 \mathrm{E}$ and at height of 283 meters. It is situated at level of 314 meters above sea level. Mardan is a district headquarters of Khyber Pakhtunkhwa. Risalpur is positioned to the south of Mardan while Charsadda, Yar Hussain and Takht Bahi and Katang are located to its west, east and north respectively. The reported average temperature is $22.2{ }^{\circ} \mathrm{C}$ while average rainfall is $559 \mathrm{~mm}$. The June is the hottest month of the year (avg. temp.33.2 ${ }^{\circ} \mathrm{C}$ ) while the coldest month is the January (avg. temperature $10.0^{\circ} \mathrm{C}$.). The driest month is October (an average rainfall of $12 \mathrm{~mm}$ ), whereas August is the wettest month (avg. 
rain fall122 mm).In district Mardan the total number of cattle, Buffaloes, sheep and goats populations are 247445, 115841, 51595 and 201333 respectively.

\section{Experimental site}

All the laboratory work was handled and processed at Parasitology Laboratory, Veterinary Research Institute, Peshawar, KPK, Pakistan.

\section{Study animals and sampling technique}

In the present study, five different areas of district Mardan were selected where ten dairy farms were visited for collection of samples. For collection of data, a questionnaire was established indicating the useful information such as breed, age, sex, health status and history of deworming. Recorded all the basic information related to bovine fasciolosis during collection of the fecal samples. All the cattle were selected randomly in dairy farms. In the present study random sampling method was applied for collection of fecal samples and data was composed. Convenience sampling technique was used for the purpose of the ease of research and simplicity of sampling. The study was continued for a period of 12 months, started from January 2018 to December, 2018.

\section{Ethics statements}

Before visiting the dairy farms, prior permission was taken from the owners of the each dairy farm and provided free veterinary services such as vaccination; treatment and other necessary suggestions were given without any fee at a time of sample collection.

\section{Sample size determination}

Since this is the first study about the prevalence and identification of associated risk factors, the sample size was calculated by using the formula assumed by [9] where prevalence of $5 \%$ and $50 \%$ absolute precision was considered as $50 \%$. According to the formula only 384 animals were to be sampled but here the sample size was increased up to 500 to increase the precise results.

\section{Study design}

A cross-sectional study was steered to determine the prevalence of bovine fasciolosis in five different selected zones of district Mardan and conducted from January, 2018 to December, 2018.

\section{Coprological examination}

All the fecal samples were directly collected from rectum of each animal using disposable gloves and mask. After collection of fecal samples, were placed in sterile open mouth bottles containing $10 \%$ formalin as a preservative. All the samples were properly sealed and labeled for necessary information such as age, sex, BCS and breed. All the samples were transported to the parasitological laboratory, Veterinary Research Institute (VRI) Peshawar. In laboratory sedimentation technique was applied to identify the fluke eggs according to the procedure as described by [10] Hansen and Perry (1994). Measured two gram of feces and placed in a cylinder containing $42 \mathrm{ml}$ of water. Then mixed properly with the help of glass rod and poured through a tea strainer for the removal of large particles. The solution was further passed through a sieve into flask and water was passed through sieve to make free of eggs. Waited for three minutes to filtrates to sediment and supernatants were removed. Then added two drops of methylene blue to filtrates and placed the entire sediment on the glass slide and placed the cover slip then viewed the slide under compound microscope (Labomed).On the basis of morphology and color characteristic, eggs of fasciola spp were identified. All the samples were stored in a refrigerator at $4{ }^{\circ} \mathrm{C}$ that were not processed within twenty four hours [11].

\section{Diagnosis of fascioliasis}

Tentative diagnosis was made on the basis of history, Physical examination and clinical examinations(Chronic diarrhea, dullness, rough body hair coat, bottle jaw, emaciation) while confirmatory diagnosis was made on 
the basis of coprological examination findings such as oval shape ova, presence of operculum and yellow brown in color.

\section{Body condition scoring (BCS)}

Scoring of the body conditions were determined by the formula as described by Mihrete et al. [12], which ranging from 0 to 5, where score (0-1) stands for poorest conditions of the body, score (2-3) stands for medium conditions of the body whereas score (4-5) stands for good health conditions of the body. All cattle under our study were divided into three classes on the basis of their body conditions such as poor (score 0-1), medium (score 2-3) and good (score 4-5). Age detection

In the present study the age groups were classified on the basis of dental formula described by [13].

\section{Management and statistical analysis}

All the collected data was properly entered in to Microsoft Excel 2010 spread sheet and analyzed by applying SPSS version 20 statistical software. Descriptive statistics was applied to analyze and set as frequencies and percentages. Pearson Chi square $\left(\chi^{2}\right)$ tests were applied to evaluate the statistical associations present between the prevalence of fasciolosis and different risk factors (age, sex, body conditions, breeds). A $\mathrm{P}<0.05$ was considered significant in all statistical analysis

\section{Results}

Overall prevalence of bovine fascioliasis

The result of the current study exposed $42.8 \%$ overall prevalence of bovine fasciolosis in district Mardan as described in (Table 1).

Table 1. Overall prevalence of Fasciolosis in bovines

\begin{tabular}{|c|c|c|}
\hline $\begin{array}{c}\text { Total number of animals } \\
\text { examined }\end{array}$ & $\begin{array}{c}\text { Total number of positive cases } \\
\text { for Fasciola spp }\end{array}$ & Overall Prevalence (\%) \\
\hline 500 & 214 & $42.8 \%$ \\
\hline
\end{tabular}

\section{Bovine fasciolosis associated with age}

In the present study, the total numbers of animals were divided in three age groups such as $\geq 1-3$ years, 4-6 years and 7-9 years. As a result, the highest prevalence was recorded in the cattle at the age of $\geq 1-3$ years $(48.82 \%)$ followed by $4-6$ years $(39.74 \%)$ while the lowest at the age of 7-9 years $(39.65 \%)$ and statistically significant variations $(\mathrm{P}<0.001)$ was observed among age group $\geq 1-3$ and others two age groups 4-6 years and 7-9 years as presented in (Table 2).

Table 2. Age wise prevalence of clinical fascioliasis

\begin{tabular}{|c|c|c|c|c|}
\hline $\begin{array}{c}\text { Age group } \\
\text { years) }\end{array}$ & $\begin{array}{c}\text { Total No of cattle } \\
\text { Examined }\end{array}$ & Total No. of cattle positive & Prevalence (\%) & P-value \\
\hline$\geq 1-3$ & 170 & 83 & $48.82 \%$ & $\mathrm{p}<0.001$ \\
\hline $4-6$ & 156 & 62 & $39.74 \%$ & \\
\hline $7-9$ & 174 & 69 & $39.65 \%$ & \\
\hline Total & 500 & 214 & $42.8 \%$ & \\
\hline
\end{tabular}

(*Significant difference at $\mathrm{p}<0.05$ )

Bovine fascioliasis associated with breeds In the present study, breed wise prevalence of fasciolosis was also studied between local and cross friesian breeds where the highest prevalence was observed in cross friesian cattle $(46.78 \%)$ followed by local cattle $(42.90 \%)$. There was high resistance to fasciolosis in local breeds than cross friesians and statistically non-significant $(\mathrm{P}>0.229)$ association was observed (Table 3 ). 
Table 3. Prevalence of Bovine fasciolosis on the basis of local and cross friesian breeds

\begin{tabular}{|c|c|c|c|c|}
\hline $\begin{array}{c}\text { Breeds(Risk } \\
\text { factors) }\end{array}$ & $\begin{array}{c}\text { Total number of } \\
\text { Examined Animals }\end{array}$ & $\begin{array}{c}\text { Total number of Positive } \\
\text { Animals }\end{array}$ & Prevalence (\%) & P-value \\
\hline Local & 282 & 112 & $42.90 \%$ & $\mathrm{p}>0.229$ \\
\hline Cross Friesians & 218 & 102 & $46.78 \%$ & \\
\hline Total & 500 & 214 & & \\
\hline
\end{tabular}

$(*$ Significant difference at $\mathrm{p}<0.05)$

\section{Bovine fascioliasis associated with sex}

In the present study, the highest prevalence of fasciolosis was reported in female $(49.03 \%)$ cattle while lower in male
$(32.63 \%)$ as presented in (Table 4) and statistically significant variations $(\mathrm{P}<0.003)$ were recorded.

Table 4. Sex wise prevalence of clinical fasciolosis in cattle

\begin{tabular}{|c|c|c|c|c|}
\hline Sex group & $\begin{array}{c}\text { Total number of examined } \\
\text { animals }\end{array}$ & $\begin{array}{c}\text { Total number of positive } \\
\text { animals }\end{array}$ & Prevalence (\%) & P-value \\
\hline Male & 190 & 62 & 32.63 & $\mathrm{p}<0.003$ \\
\hline Female & 310 & 152 & 49.03 & \\
\hline Total & 500 & 214 & $42.8 \%$ & \\
\hline
\end{tabular}

(*Significant difference at $\mathrm{p}<0.05)$

Bovine fasciolosis associated with body condition score (BCS)

In the present study, the highest rate of infection was recorded in those animals having poor body conditions $(49.54 \%)$ followed by medium body conditions
(45.61\%) while the lowest prevalence was recorded in those animals having good body conditions (37.27\%) and statistically nonsignificant variations $(\mathrm{p}>0.373)$ was recorded (Table 5).

Table 5. Prevalence of Bovine fasciolosis on the basis of body conditions score

\begin{tabular}{|c|c|c|c|c|}
\hline BCS(Risk factors) & $\begin{array}{c}\text { Total number of } \\
\text { examined animals }\end{array}$ & $\begin{array}{c}\text { Total number of } \\
\text { positive animals }\end{array}$ & Prevalence (\%) & P-value \\
\hline Poor & 109 & 54 & 49.54 & $\mathrm{p}>0.373$ \\
\hline Medium & 171 & 78 & 45.61 & \\
\hline Good & 220 & 82 & 37.27 & \\
\hline Total & 500 & 214 & & \\
\hline
\end{tabular}

(*Significant difference at $\mathrm{p}<0.05)$

\section{Discussion}

The results of our current study exposed $42.8 \%$ overall prevalence of bovine fasciolosis in district Mardan. Our findings are close to $[14,15]$, who reported $32(\%)$ and $32.6(\%)$ prevalence in North Ethiopia and Abay district respectively. Similarly our results are little higher than [16-18] who reported $30.02 \%, 33.42 \%$ and $36.72 \%$ in Dangila, North Gonder and in and around Bahir Dar respectively. Our results are similar to the results recorded by $[19,20]$ who reported $43.25 \%$ and $41.41 \%$ prevalence in around Assela and N.W. Ethiopia. Our results are higher than findings reported by [21-25] who are $14.05 \%, 15.9 \%, 12.7 \%$, $19.1 \%, 15.9 \%$ and $12.4 \%$ respectively. The differences in prevalence of fasciolosis in cattle might be due to methodology of study, environmental conditions, immune status of the animals, population of snails, regular 
deworming programme, management system and provision of veterinary facilities.

In the present study, the highest prevalence was recorded in the cattle at age group of $\geq 1$ 3 years (48.82\%) followed by 4-6 years $(39.74 \%)$ while lowest at $7-9$ years $(39.65 \%)$ and statistically significant variations $(p<0.05)$ was observed between young age group and adults. At early life the highest prevalence was observed in bovines and lower at older ages. Age is important risk factors affecting the prevalence of fasciolosis significantly. Our study is agreeing with the findings reported by [27] who also reported that prevalence of fasciolosis decrease as age increased. He reported $28.7 \%$ bovine fasciolosis in young animals while in adults $25.7 \%$. Similar findings were also reported by $[16,28,29]$ where it was stated that as age increases, resistance to fasciolosis also increases. At adult age, the resistance is due to severe fibrosis of liver which weakens the movement of immature flukes, calcification and stenosis of bile duct provides unfavorable environment for adult parasites and finally result in their expulsion [30]. Our statement is in line with the findings reported by [31] who pointed out that younger cattle are highly susceptible to fasciolosis.

In the present study breed wise prevalence of bovine fasciolosis was also determined where the highest prevalence was observed in cross friesian cattle $(46.78 \%)$ followed by local cattle $(42.90 \%)$ and statistically insignificant ( $>0.0 .229)$ association was observed. Similar findings were also reported by [32, 33]. Our results are close to [32] who recorded highest occurrence of fasciolosis in cross breed cattle (64.29\%) than local breeds $(35.71 \%)$ in district Chittagong Bangladesh. [33] also reported highest prevalence of fasciolosis in cross breeds calves than local breed calves. He further added that our farmers cannot fulfill the basic requirements of the Friesian calves, result in lowering the resistance to fasciolosis.
In this study, the highest prevalence of fasciolosis was reported in female $(49.03 \%)$ cattle than male $(32.63 \%)$. Our results are close to the findings reported by [34-36]. [34] Who did report that female cattle $(41.3 \%)$ were highly susceptible to fasciola infection than male (13.8\%). Our findings are also similar to the findings reported by [37], where highest prevalence was recorded in female cattle $(70.3 \%)$ than male $(55.23 \%)$. Our results are also close to the findings reported by [36] where higher fasciola infestation was reported in female $(52.2 \%)$ cattle than male $(48.9 \%)$. [37] also pointed out prevalence of higher prevalence of fasciolosis in female (45.08\%) followed by male $(20.89 \%)$.Our results are not agreed with the findings reported by [38] where higher prevalence was recorded in male (14\%) than female $(9.8 \%)$ but the exact cause is unknown here, however it may be due to poor physical and immune status of female than male cattle which make females more prone to fasciola infection as reported by $[39,40]$. In the present study, the highest rate of infection was recorded in those animals having poor body conditions (49.54\%) followed by medium body conditions (45.61\%)while the lowest prevalence was recorded in those animals having good body conditions $(37.27 \%)$ and statistically nonsignificant variations $(\mathrm{p}>0.373) \quad$ was recorded. Our results are not agreed with the findings reported by [41] where significant association was reported between body conditions and prevalence of fasciolosis. These variations may be due to epidemiology of Fasciola spp, study area, and study design. Our results are different from $[42,43]$.The highest prevalence in poor condition animals might be due to chronic disease and concurrent infection enhance the susceptibility of fasciolosis. As a result excessive weight loss was observed in those cattle suffering from fasciolosis and the most common sign was loss of weight $[16,29]$. 


\section{Conclusion and recommendations}

It was concluded that bovine fasciolosis is highly prevalent in the study area with an overall prevalence was $42.8 \%$. Bovine fasciolosis are responsible for heavy economic losses in form of low milk production and poor weight gain. Bovine fasciolosis is the primary concerned disease in the study area so it should be mentioned in priority list. This study explored that age is the key risk factor in bovine fasciolosis. Fasciolosis was one of the major constrain in development of livestock in district Mardan, Pakistan. The climate of our studying area is humid and hot, which is susceptible for growth and development of parasites. To control parasitic infection in bovines, epidemiological research is important for proper control. In Pakistan, few studies are available regarding bovine fasciolosis in the current study area.This study will help other researchers and field workers to overcome prevalence of fasciolosis in different parts of our country. As a result it was concluded from the present study that bovine fasciolosis is highly prevalent in the study area with an overall prevalence is $42.8 \%$.Bovine fasciolosis are responsible for heavy economic losses in form of low milk production and poor weight gain. Bovine fasciolosis is the primary concerned disease in the study area so it should be mentioned in priority list. This study explored that age is the key risk factor in bovine fasciolosis. I recommend the following suggestions for future control such as regular use of different anthelmintic (flukicides) to reduce resistant to the drug proper control of intermediate hosts (snails) by spraying copper sulphate, avoid grazing of animals in heavily populated snail's area.

\section{Authors' contributions}

Conceived and designed the experiments: NU Khan \& S Sultan, Performed the experiments: H Ali, A Ali \& MS Sarwar, Analyzed the data: T Usman \& M Hussain,
Contributed materials/ analysis/tool: M Ali, I Ullah \& F Rabbani, Wrote the paper: A Rahman \& AU Khan.

\section{Acknowledgement}

We all are very gratified to the District Director Livestock and Dairy development Mardan for their continuous support by providing field staff for collection of fecal samples.

\section{References}

1. Rehman A, Jingdong L \& Du Y (2015). Last five years Pakistan economic growth rate (GDP) and its comparison with China, India and Bangladesh. Inter J Technol Enhancements Emerg Eng Res 4(1): 8186.

2. Troncy PM (1989). Helminthes of livestock and poultry in Tropical veterinary parasitology. CAB international, UK, pp 63-73.

3. Lazara R, Vazquez A, Domenech I \& Robertson LJ (2010). Fascioliasis: can Cuba conquer this Emerging parasitosis? Trends in Parasitol 26: 26-34.

4. Abdulhakim Y \& Addis M (2012). An Abattoir Study on the Prevalence of Fasciolosis in Cattle, Sheep and Goats in Debre Zeit Town, Ethiopia. Global Veterinaria 8(3): 308-314.

5. Yusuf M, Nuraddis I, Tafese W \& Deneke $Y$ (2016). Prevalence of Bovine Fasciolosis in Municipal Abattoir of Haramaya, Ethiopia. Food Science and Quality Management, pp 48.

6. Asressa Y (2011). Study of prevalence of major bovine ŇZŬĞ ŝñ $\breve{G} c t Z ̌ n$ at Andassa livestock research, North West, Ethiopia, Gondar, Ethiopia.

7. Biniam T, Hanna A \& Sissay G (2012). Coprological prevalence of bovine fasciolosis in and around woreta, Northwestern Ethiopia. J Vet Med and Ani Health 4: 89-94.

8. Bowman DD, Lynn RC, Eberhard ML \& Ana A (2003) Parasitology for veterinarians.8thed. New York, Saunders, pp 115-122. 
9. Thrusfield M (2005). Veterinary Epidemiology. In Thrusfield M (Eds.) (3rd edn.), Blackwell Publishing, New Jersey, United States, pp 345-543.

10. Hansen J \& Perry B (1994). The epidemiology, diagnosis and control of helminth parasites of ruminants. A hand book of International laboratory for research on Animal Disease, Nairobi, Kenya, pp 31-36.

11. FAO (2003). Diagnostic manual on meat inspection for developing countries.

12. Mihrete $B$, Haftom $T \&$ Yehenew $G$ (2010). Bovine fasciolosis: Prevalence and its economic loss due to liver condemnation at Adwa municipal Abattoir North Ethiopia. EJAST 1(1): 39-47.

13. Johnson RF (1998). The stockman`s hand book by Ensminger, 2nd edn, pp 539.

14. Richard W (1993). Dairying.Tropical Agriculturalist. In Richard W (Eds.) (1st Edn) Macmillan Press London, United Kingdon, pp 43-48.

15. Daksa G, Abdisa M, Desalegn J, Negasa F \& Assefa K (2016). Abattoir Survey on Prevalence of Bovine Fasciolosis in Guduru and AbayChomaan Districts. World J Agric Sci 12(2): 111-118.

16. Asmare G \& Samuel D (2015). Prevalence of Bovine Fasciolosis and Its associated Risk Factor in and Around Dangila District, Awi Administration Zone, Northwestern Ethiopia. European J of Biol Sci 7(3): 114-119.

17. Mesfin A \& Yilma J (2000). Dry Season Bovine Fasciolosis in Northwestern Part of Ethiopia. Revue deMédicineVétérinaire 151: 493-500.

18. Fikirtemariam A, Jemere B, Yeshwas F \& Mussie H (2013). Study on prevalence of bovine fasciolosis in and around Bahirdar, Ethiopia. Vet J 17(1): 1-11.

19. Buniamt T, Hanna A \& Sissay G (2013). Coprological prevalence of bovine fasciolosis in and around woreta, Northwestern Ethiopia. J Vet Med and Ani Health 4: 89-94.

20. Yitayal G, Mebratu G \& Abebe T (2015). Prevalence of bovine fasciolosis in and around Bahir Dar, North West Ethiopia. $J$ of Parasitol and Vector Biol 7: 74-79.

21. Solomon W \& Abebe W (2007). Effects of a strategy antehelmtic treatment intervention of bovine fasciolosis. A conducted in facilities in endemic area in North West Ethiopia. Vet J 11: 59-68.

22. Fufa A, Loma A, Bekele M \& Alemayew R (2009). Bovine Fasciolosis: Coprological, Abattoir survey and its economic impact due to liver condemnation at Soddo municipal Abattoir southern Ethiopia Trop. Animal Health Prod 42(2): 289-292.

23. Swai E S \& Ulicky E (2009). An evaluation of the economic losses resulting from condemnation of cattle livers and loss of carcass weight due to Fasciolosis: a case study from Hai town abattoir, Kilimanjaro region, Tanzania. Livestock Res for Rural Devel 21(11): 186.

24. Nuraddis I, Wasihun P \& Tolosa T (2010). Prevalence of Bovines Fasciolosis and Economic Importance due to Liver Condemnation at Kombolcah Industrial Abattoir, Ethiopia. The Internet J Vet Med 8(2): 78-84.

25. Tilahun Z, Nemomsa D, Himanot H \& Girma K (2014). Study on prevalence of Bovine Fasciolosis at Nekemte Veterinary clinic, East Wolega Zone, Oromia, Ethiopia. European J of Biol Sci 6: 40-45.

26. Negesse MA \& Mohammed GA (2014). Prevalence and Economic Significance in Southern Ethiopia. Acta Parasitologica Globalis 5: 70-72.

27. Mohammed Y, Nuraddis I, Wubit T \& Yosef D 2016). Prevalence of Bovine Fasciolosis in Municipal Abattoir of Haramaya, Ethiopia. Food Sci and Quality Manage 4: 34-40.

28. Legesse $\mathrm{S}$, Tsegaye $\mathrm{S}$, Lamesgen $\mathrm{S}$, Wolelaw Y \& Garikipati D (2017). Coprological Prevalence and Associated Risk Factors of Bovine Fasciolosis in and Around Zenzelma Bahir Dar Ethiopia. Eur Exp Biol 7: 5-34.

29. Samuel D \& Asmare G (2015). Prevalence of Bovine Fasciolosis and Its associated 
Risk Factor in and Around Dangila District, Awi Administration Zone, Northwestern Ethiopia. European J of Biol Sci 7(4): 124-129.

30. Gebretsadik B, Kassahun B \& Gebrehiwot $\mathrm{T}$ (2009). Prevalence and economic Significance of fasciolosis in cattle in Mekelle Area of Ethiopia. Trop Animal Health and Prod 41(7): 1503-1504.

31. Radostits D, Blood B \& Gray C (2007) Vet Medicine Text Book of the Diseases of Cattle, Sheep, Goat, Pig and Horse 8th edn. ELBS and Bailleretindal.

32. Khatun MS, Assaduzzaman M, Pallab MS \& Chakraborty P (2015). Risk factors analysis of fascioliasis in two geo-climatic regions of Bangladesh. Inter J of Sci Res 4(11): 41-43.

33. Hoque MM, Alam $M$ \& Rahman ML (1998). Helminth infection in cattle of Feni district of Bangladesh. The Bangladesh Vet 9: 105-106.

34. Affroze S, Begum N, Islam MS, Rony SA, Islam MA and Mondal MMH (2013). Risk factors and gross pathology of bovine liver fluke infection at Netrokona district, Bangladesh. J of Animal Sci Adv 3(2): 8390.

35. Karim MR, Mahmud MS \& Giasuddin M (2015). Epidemiological study of bovine fasciolosis: prevalence and risk factor assessment at Shahjadpurupazila of Bangladesh. Immunol and Infectious Dis 3(3): 25-29.

36. Nath KL, Phiri AM, Phiri IK, Sikasunge CS \& Monrad J (2016). Prevalence of Fasciolosis in Zambian Cattle Observed at Abattoirs with Emphasis on Age Sex and Origin. J Vet Med B 52(9): 414-416.
37. Bhutto B, Arijo A, Phullon MS \& Rind R (2012). Prevalence of fascioliais in buffaloes under different agroclimatic areas of Sindh province of Pakistan. Inter $J$ of Agric and Biol 14(2): 241-245.

38. Sumbal Haleem, Shadab, Faiza, Sadaf Niaz, Hameed Ur Rehman, Shazeb Sajad, Naveeda Akhtar Qureshi \& Muhammad Kabir (2016). Prevalence of fascioliasis in cows and sheep in district Mardan (KPK), Pakistan. J of Entomol and Zool Stu 4(3): 330-334.

39. Chowdhury SMZH, Mondal MMH, Islam FMS, Taimur MJFA, Biswas HR \& Ershaduzzaman M (1994). Prevalence of fasciloiasis in cattle in Saver, Dhaka. Indian Vet J 71(2): 121-123.

40. Molina EC, Gonzaga EA \& Lumbao LA (2005). Prevalence of infection with Fasciola gigantica and its relationship to carcass and liver weights, and fluke and egg counts in slaughter cattle and buffaloes in Southern Mindanao, Philippines. Trop Animal Health and Prod 37(3): 215-221.

41. Feleke E \& Girma D (2018). The Prevalence and Economic Importance of Bovine Fasciolosis at Debre Birhan Municipal Abattoir. Inter J of Current Res 10(1): 63812-63817.

42. Pfukenyi D \& Mukaratirwa S (2004). A Retrospective Study of the Prevalence and Seasonal Variation of Fasciola gigantica in Cattle Slaughtered in the Major Abattoirs of Zimbabwe between 1990 and 1999. Onderstepoort J Vet Res 71(3): 181-187.

43. Dwinger RH, Leriche PD \& Kuhne GI (1982). Fasciolosis in beef cattle in North West Argentina. Trop Animal Health under Prod 14(3): 167-17. 